\title{
Acute neurosurgical management of traumatic brain injury and spinal cord injury in French armed forces during deployment
}

\author{
Arnaud Dagain, MD, ${ }^{1}$ Olivier Aoun, MD, ${ }^{2}$ Aurore Sellier, MD, ${ }^{1}$ Nicolas Desse, MD, ${ }^{1}$ \\ Christophe Joubert, MD, ${ }^{1}$ Nathan Beucler, MD, ${ }^{1}$ Cédric Bernard, MD, ${ }^{1}$ Mathilde Fouet, MD, ${ }^{3}$ \\ Jean-Marc Delmas, MD, ${ }^{3}$ and Renaud Dulou, MD ${ }^{3}$
}

${ }^{1}$ Service de Neurochirurgie, Hôpital d'Instruction des Armées Sainte Anne, Toulon; ${ }^{2}$ The 5th Armed Forces Medical Center, Strasbourg; and ${ }^{3}$ Service de Neurochirurgie, Hôpital d'Instruction des Armées Percy, Clamart, France

\begin{abstract}
This article aims to describe the French concept regarding combat casualty neurosurgical care from the theater of operations to a homeland hospital. French military neurosurgeons are not routinely deployed to all combat zones. As a consequence, general surgeons initially treat neurosurgical wounds. The principle of this medical support is based on damage control. It is aimed at controlling intracranial hypertension spikes when neuromonitoring is lacking in resource-limited settings. Neurosurgical damage control permits a medevac that is as safe as can be expected from a conflict zone to a homeland medical treatment facility. French military neurosurgeons can occasionally be deployed within an airborne team to treat a military casualty or to complete a neurosurgical procedure performed by a general surgeon in theaters of operation. All surgeons regardless of their specialty must know neurosurgical damage control. General surgeons must undergo the required training in order for them to perform this neurosurgical technique.
\end{abstract}

https://thejns.org/doi/abs/10.3171/2018.9.FOCUS18368

KEYWORDS neurosurgical damage control; decompressive craniectomy; war surgery; head injury

$\mathrm{W}$ AR surgery is classically described as an emergency surgery performed in a hostile environment with limited human and equipment resources. The combat casualty-specific management is based on optimal time periods as defined by the North Atlantic Treaty Organization (NATO) from initial extraction to evacuation to France..$^{15}$ The objective is to reach a surgical outpost (role 2) in less than 1 hour in order to access "damage control" early surgery.

The French Military Health Service has 2 military neurosurgery departments located in the Clamart and Toulon military teaching hospitals, respectively. These 2 structures are level I trauma centers admitting military and civilian casualties. Each neurosurgery unit is composed of 5 neurosurgeons who are deployable to theaters of operations within role 3 hospitals (cf. NATO regulations). ${ }^{15}$ Their primary mission is to treat military casualties repatriated from conflict zones as well as local French citizens.
The neurosurgery wards are general neurosurgery departments with strong skills in head and spine trauma.

This article aims to describe the French concept regarding combat casualty neurosurgical care from the theater of operations to a homeland hospital.

\section{Deployment of French Military Neurosurgeons}

Neurosurgical combat casualty care has gradually evolved with the different conflicts. ${ }^{1,15}$ During the First Gulf War (1990-1991), a French military neurosurgeon was deployed for the first time, within a role 3 facility (lacking CT imaging) in Riyadh, Saudi Arabia, for 50 days. Only 2 neurosurgical operations were performed: the patients had presented with a craniocerebral head injury and an orbitocerebral wound, respectively.

The French military presence in the Balkans was mainly as follows: Bosnia (1992-2009) and Kosovo (19992014). It essentially consisted of peacekeeping operations. 
TABLE 1. Organization of French medical support during deployment

\begin{tabular}{cc}
\hline Role & Characteristics \\
\hline 1 & $\begin{array}{c}\text { A medical military outpost deployed as near as possible to the combat zone providing first aid, immediate lifesaving measures, and triage. In ad- } \\
\text { dition, routine sick call and the management of minor sick and injured personnel for immediate return to duty are a function of this level of care. }\end{array}$ \\
\hline 2 & $\begin{array}{c}\text { Provides evacuation from role/echelon } 1 \text { facilities, triage and resuscitation, treatment, and holding of patients until they can be returned to duty } \\
\text { or evacuated, as well as emergency dental treatment. Includes general surgical capabilities for "damage control" surgery. }\end{array}$ \\
\hline $2+$ & A role 2 unit with CT imaging and sonography. \\
\hline 3 & $\begin{array}{c}\text { This field hospital includes additional capabilities, including specialist diagnostic resources, specialist surgical and medical capabilities, preven- } \\
\text { tive medicine, food inspection, dentistry, and operational stress management teams. Care is pursued to complete stabilization before air } \\
\text { medevac. }\end{array}$ \\
\hline $\begin{array}{c}\text { Comprises specialist surgical and medical procedures, reconstruction, rehabilitation, and convalescence. This level of care is usually highly } \\
\text { specialized, time-consuming, and normally provided in the country of origin. }\end{array}$ \\
\hline
\end{tabular}

As a consequence, this conflict was characterized by the absence of French military neurosurgeons. Head injuries were managed by an orthopedic or a general surgeon. Few epidemiological data are available regarding this period of time. In 2000, after experiencing logistical difficulties in sending a neurosurgeon to Sarajevo to manage a craniocerebral wound case prior to the patient's medevac, we decided to create a mobile neurosurgical unit. This team includes neurosurgeons and resuscitation specialists and has deployed 37 times since 2001, mainly in Africa, performing 27 surgeries on site (head $[n=20]$ and spine $[n=7]){ }^{10}$

From 2001 to 2013, French armed forces deployed to Afghanistan as part of the NATO-led International Security Assistance Force (ISAF), and were confronted by nongovernmental rebels. It was an asymmetrical engagement (conflict between professional soldiers and insurgents), characterized by unpredictable combat actions, without a clearly defined front line, and with use of homemade explosive devices, which were responsible for multiple injuries. ${ }^{2}$ French troops were fighting against the insurgents in the remote Uzbin and Tagab valleys. Following the increasing number of head injuries in 2009, neurosurgeons were deployed to Afghanistan at the Kabul International Airport role 3 hospital starting in March 2010.9,15 French casualties would be treated in role 1 medical outposts and/or directly referred to the Kabul International Airport role 3 hospital. As a consequence, role 2 tactical surgical field hospitals were not deployed. From March 2010 to June 2013, neurosurgical operations represented $10.6 \%$ of all the role 3 admissions, of which $52 \%$ were emergency interventions. In this asymmetrical warfare, the typical neurosurgical patient was an explosion casualty, with penetrating head wounds (58\% of cases), and polytrauma with associated injuries predominantly in the face, limbs, and chest $(83 \%$ of cases). A transfusion was needed in $79.1 \%$ of cases. ${ }^{5}$ Onethird of these patients died during care (killed in action, at the emergency room, or postoperatively). ${ }^{9}$

Since 2014, France has been engaged in the war on terrorism in the Sahelo-Saharan band, also called Opération Barkhane in French (Operation Barkhan). A "barchan" or "barkhan" means "a moving crescent-shaped sand dune" in Kazakh. This theater of operations extends thousands of kilometers, representing 5 million $\mathrm{km}^{2}$, and including Mauritania, Mali, Burkina Faso, Niger, and Chad. Similarly to the Afghan asymmetrical warfare, soldiers have been presenting with explosion-related penetrating injuries. However, the Sahelo-Saharan zone is approximately 7.5fold larger than Afghanistan, requiring tactical medevacs from role 1 medical outposts to role 2 or $2+$ tactical surgical field hospitals for which helicopters or CASA/IPTN CN-235 transport aircraft are used (Table 1). This type of asymmetrical conflict, encompassing a vast area, requires extremely mobile forward surgical structures with no neurosurgeon or CT imaging. To reduce these impediments to receiving optimal health care, the role 2 orthopedic and general (gastrointestinal or urology) surgeons are trained to treat head and spine injuries. This training, which includes learning the operative indications and simple surgical techniques, is based on the neurosurgical damage control principles. Patients are then transported to the role $2+$ hospital in Gao, Mali, where the mobile neurosurgical team completes stabilization before patients are transported via air medevac to a role 4 unit in France.

\section{Damage Control Principles}

Rotondo et al. were the first to define damage control in 1993 as a 2-step surgery separated by a resuscitation interval. ${ }^{20}$ Damage control includes starting with a life-saving, emergency surgical procedure step, followed by a second resuscitation step (for correcting coagulopathy, hypothermia, and acidosis), and finally the third, definitive surgical step on a stabilized patient. This 2-step surgical procedure originates from a Navy concept encompassing all temporary measures aimed at stopping a ship from sinking while pursuing the mission. These rescue measures are established in emergency situations (survival of the ship and its crew). Definitive repairs are deferred. These repairs depend first on the return to a safe and calm setting, and second, on the use of heavy equipment, which requires a return to port. The use of the "damage control" term in traumatology in life-threatening emergency situations is therefore appropriate, with early implementation of rescue measures to guarantee survival (unstable patient), before finally treating the injuries upon return to a calmer and safer context (stabilized patient).

This 2-step surgical therapy philosophy is in contradiction with the all-in-one-step surgery concept in which the extended intervention time (3-6 hours) induces the lethal triad of coagulopathy, hypothermia, and acidosis. The latter is responsible for nonsurgical and often fatal bleeding. 
Damage control was initially described in abdominal injuries. For Rotondo et al., ${ }^{20}$ damage control surgery includes hemostasis (intraabdominal packing) and fecal peritonitis prevention. Similarly, this concept was extended to thoracic, heart, urinary tract, eye, head, spine, and orthopedic surgeries. In all these specialties hemostasis remains the life-saving procedure, whereas other specialty-specific techniques replace fecal peritonitis prevention.

\section{Neurosurgical Damage Control Principles}

Before initiating damage control, resuscitation procedures must be performed (airway, breathing, circulation). This is essential for reducing the risk of secondary brain injury. ${ }^{19}$ Neurosurgical damage control aims at controlling cerebral bleeding and/or edema-related intracranial hypertension. ${ }^{9}$ The first surgical step is decompressive craniectomy. ${ }^{8,17}$ Damage control is part of a multidisciplinary approach to maintain and/or restore a satisfying cerebral perfusion pressure without increasing the infection risk. ${ }^{9}$ This procedure can be associated with another damage control surgical act. ${ }^{6.9}$ Neurosurgical damage control guarantees a medevac as safe as can be expected between the conflict zone and a homeland hospital. ${ }^{4,18}$ Its objective is to directly control intracranial pressure elevations, particularly when neuromonitoring is lacking due to limited resources..$^{18}$ Later, depending on the clinical course, the skull will be reconstructed using $3 \mathrm{D}$ prosthetics as soon as possible. We perform early cranioplasties (less than 3 months) wherever possible. ${ }^{9}$ We first conduct a thorough clinical, biological, and radiological infectious risk assessment. Then, after a multidisciplinary team meeting including an intensivist, a rehabilitation physician, and a neurosurgeon, we confirm the early cranioplasty indication.

In a previously published series on craniocerebral wounds in Afghanistan, we performed 11 early cranioplasties allowing a postoperative neurological improvement. ${ }^{9}$ For neurosurgeons, decompressive craniectomy is a simple, fast, and stereotyped procedure. However, for nonneurosurgeons it is a hard-to-perform, and sometimes stressful, procedure. According to Baron Larrey, French surgeon in Napoleon's Grande Armée, trephination was, "without exception, the most difficult part in military surgery." 21 Therefore, nonneurosurgeons must be trained to perform standby, early, decompressive craniectomy. A secondary and more complete surgery could be performed by a neurosurgeon after repatriation..$^{9,18}$

\section{Indications}

There is no head CT scanning available in the combat zone. For a closed head injury, surgery is indicated in the presence of unilateral mydriasis associated with neurological deterioration..$^{14,18}$ Distinguishing traumatic mydriasis from brain herniation-related mydriasis is difficult in closed head injuries. Ultrasound imaging, available at the role 2 forward surgical structures, is a useful diagnostic tool. ${ }^{9}$ According to the surgeon's experience, he or she can either drill exploratory burr holes ipsilateral to mydriasis, which can be turned into craniotomy or craniectomy in case of confirmed epidural hematoma, or perform decompressive craniectomy ipsilateral to mydriasis in order

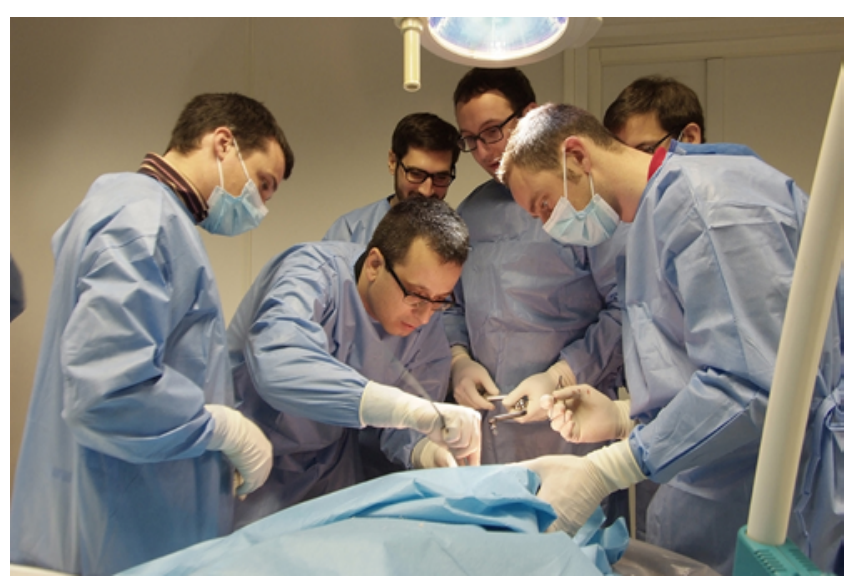

FIG. 1. Cadaver-based approach for teaching decompressive craniectomy.

to stabilize the patient prior to and during medevac. ${ }^{9,14,18}$ In all other cases (absence of mydriasis regardless of the Glasgow score, bilateral mydriasis) medical management is indicated.

For an open head injury, surgical debridement must be performed level by level. ${ }^{9,14} \mathrm{~A}$ craniectomy may be associated on the ipsilateral side of mydriasis. ${ }^{8,9,13}$ In all cases, bilateral mydriasis contraindicates surgery. ${ }^{9,14}$ In remote and isolated settings these casualties are considered expectant patients (morituri T4). ${ }^{19}$

If available, CT scanning is quite handy for exploring impaired consciousness. ${ }^{9}$ Indications are similar to those in civilian practice. In war situations, the most frequent injuries are either diffuse axonal injuries or penetrating wounds. ${ }^{9} 16$ Hematomas (extradural or subdural) and cerebral edema are less common.

\section{Nonneurosurgical Far-Forward Damage Control}

Because French military neurosurgeons are lacking and theaters of operation are progressively increasing with expanding distances, it is not possible to routinely deploy a French neurosurgeon. Since the Balkans conflict, we have assembled an airborne mobile neurosurgical team. Until this team arrives, a nonneurosurgeon will stabilize the patient by performing the first step of damage control. As a consequence, the basic craniectomy techniques (reverse question-mark temporofrontoparietal incision, performing a bone flap by manual trephine-made burr holes and Gigli saw, opening dura mater, cerebral wound debridement) are taught to all French military surgeons during the advanced deployment surgery course (in French: Cours Avancé de Chirurgie en Missions Extérieures; CACHIRMEX). ${ }^{4}$ This 5-module workshop allows orthopedic and general surgeons to learn war surgery basics with all specialties encompassed. Module 3 focuses on head and neck. Each course starts with a lecture followed by practice on human cadavers (Fig. 1). Instructors stress the strict indications of this procedure and its main pitfalls, using step-by-step methods for learning the surgical techniques (Fig. 2). Insertion of an external ventricular drain, which is part of the first surgical step, is not taught because we find this procedure too specialized. 


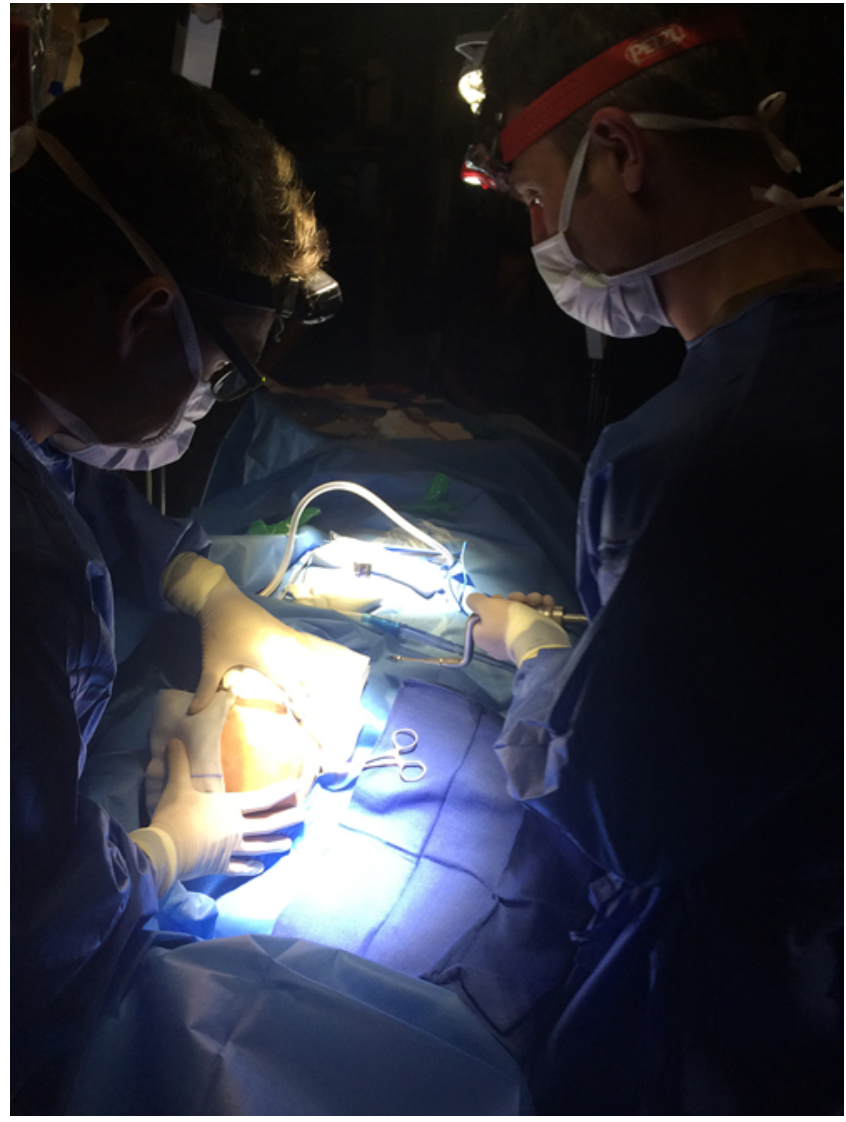

FIG. 2. Teaching head surgery combat casualty care on a mannequin.

In practice, the first surgery in the theater of operations is performed by an orthopedic or a general surgeon (gastrointestinal, thoracic, or urinary tract surgeon). It includes craniocerebral wound debridement, even decompressive craniectomy. During this first step, the military neurosurgeons who are on duty in France will deliver their instructions through telemedicine setups. They will guide and validate this first procedure before approving the medevac (depending on the injury severity) to a role 4 unit in France by the mobile neurosurgical team. ${ }^{3,7,10}$

While waiting for the air medevac on a medically equipped Falcon aircraft, the patient undergoes neuroresuscitation in the theater of warfare. During the flight, the patient is monitored by an intensivist who has at his or her disposal ultrasound imaging with transcranial Doppler, and sometimes an intracranial pressure sensor. Currently, no neurosurgical procedure is possible on board the aircraft. ${ }^{10}$

The second surgical step is performed in France in a role 4 hospital. This stage is about dealing with eventual complications (CSF leakage, frontal sinus cranialization, reoperation for a hematoma, infection). More specifically, it is a bone reconstruction step performed using 3D scanning for prosthetic design.

\section{Spinal Surgical Management}

Spine surgery in the French armed forces is only per- formed by neurosurgeons. As a consequence, a soldier sustaining a spinal injury during deployment is immobilized and then flown to a hospital in France to receive appropriate care. The management of this type of trauma requires advanced imaging with CT scans and MRI, along with a large volume of spine surgery ancillary equipment, which is unavailable in theaters of operation. Moreover, many publications have shown that early treatment increased repeat surgeries and morbidity. ${ }^{12,22}$ Two situations can require early management by the mobile neurosurgical team: occurrence or worsening of a neurological deficit or a significant loss of CSF. ${ }^{11}$

\section{Conclusions}

Neurosurgical damage control permits a medevac that is as safe as can be expected from a conflict zone to the homeland medical treatment facility. Damage control is aimed at controlling intracranial hypertension spikes when neuromonitoring is lacking in resource-limited settings. This procedure must be known to all surgeons, regardless of their specialty. General surgeons must undergo the required training in order for them to perform this neurosurgical technique. It is essential, however, that a senior neurosurgeon confirms the indication before the cranial surgery is performed by a general surgeon. The neurosurgery training of French military surgeons working in the fields of orthopedic, urinary tract, thoracic, and gastrointestinal surgery will continue in the future. Nevertheless, depending on the mission and casualties, a neurosurgeon might be deployed to a role 2 structure, offering his or her expertise to assist colleagues in treating skull and spine injuries.

\section{References}

1. Agarwalla PK, Dunn GP, Laws ER: An historical context of modern principles in the management of intracranial injury from projectiles. Neurosurg Focus 28(5):E23, 2010

2. Belmont PJ Jr, McCriskin BJ, Sieg RN, Burks R, Schoenfeld AJ: Combat wounds in Iraq and Afghanistan from 2005 to 2009. J Trauma Acute Care Surg 73:3-12, 2012

3. Bertani A, Menguy P, Delmas JM, Launay F, Mathieu L, Candoni P, et al: [Assessment of surgical teleconsultations in a developing country: two years of experience in Djibouti.] Med Sante Trop 22:405-408, 2012 (Fr)

4. Bonnet S, Gonzalez F, Poichotte A, Duverger V, Pons F: Lessons learned from the experience of visceral military surgeons in the French role 3 Medical Treatment Facility of Kabul (Afghanistan): an extended skill mix required. Injury 43:1301-1306, 2012

5. Bordes J, Joubert C, Esnault P, Montcriol A, Nguyen C, Meaudre E, et al: Coagulopathy and transfusion requirements in war related penetrating traumatic brain injury. A single centre study in a French role 3 medical treatment facility in Afghanistan. Injury 48:1047-1053, 2017

6. Breeze J, Blanch R, Baden J, Monaghan AM, Evriviades D, Harrisson SE, et al: Skill sets required for the management of military head, face and neck trauma: a multidisciplinary consensus statement. J R Army Med Corps 164:133-138, 2018

7. Brévart C, Bertani A, Abdourahman Aden H, Menguy P, Dulou R: Severe vertex epidural hematoma in a child: a case report of a management without expert neurosurgical care. Case Rep Surg 2011:476416, 2011 
8. Charry JD, Rubiano AM, Puyana JC, Carney N, David Adelson P: Damage control of civilian penetrating brain injuries in environments of low neuro-monitoring resources. Br J Neurosurg 30:235-239, 2016

9. Dagain A, Aoun O, Bordes J, Roqueplo C, Joubert C, Esnault $P$, et al: Management of war-related ballistic craniocerebral injuries in a French role 3 hospital during the Afghan Campaign. World Neurosurg 102:6-12, 2017

10. Dulou R, Dagain A, Delmas JM, Lambert E, Blondet E, Goasguen O, et al: The French mobile neurosurgical unit. Neurosurg Focus 28(5):E13, 2010

11. Dulou R, Delmas JM, Dagain A, Yordanova Y, Pernot P: Is it worth performing suture of the cauda equina roots after traumatic penetrating lumbar injury in a combat support Hospital? Acta Neurochir (Wien) 157:1087-1088, 2015

12. Formby PM, Wagner SC, Kang DG, Van Blarcum GS, Pisano AJ, Lehman RA Jr: Reoperation after in-theater combat spine surgery. Spine J 16:329-334, 2016

13. George ED, Dagi TF: Military penetrating craniocerebral injuries. Applications to civilian triage and management. Neurosurg Clin N Am 6:753-759, 1995

14. Giannou C, Baldan M (eds): War Surgery. Working With Limited Resources in Armed Conflict and Other Situations of Violence. Geneva: ICRC, 2010 (https://www.icrc. org/eng/assets/files/other/icrc-002-0973.pdf) [Accessed October 9, 2018]

15. Joubert C, Dulou R, Delmas JM, Desse N, Fouet M, Dagain A: Military neurosurgery in operation: experience in the French role-3 medical treatment facility of Kabul. Acta Neurochir (Wien) 158:1453-1463, 2016

16. Klimo P Jr, Ragel BT: Introduction: military neurosurgery, past and present. Neurosurg Focus 28(5):Introduction, 2010

17. Moon JW, Hyun DK: Decompressive craniectomy in traumatic brain injury: a review article. Korean J Neurotrauma 13:1-8, 2017

18. Ragel BT, Klimo P Jr, Martin JE, Teff RJ, Bakken HE, Ar- monda RA: Wartime decompressive craniectomy: technique and lessons learned. Neurosurg Focus 28(5):E2, 2010

19. Rosenfeld JV, Bell RS, Armonda R: Current concepts in penetrating and blast injury to the central nervous system. World J Surg 39:1352-1362, 2015

20. Rotondo MF, Schwab CW, McGonigal MD, Phillips GR III, Fruchterman TM, Kauder DR, et al: 'Damage control': an approach for improved survival in exsanguinating penetrating abdominal injury. J Trauma 35:375-383, 1993

21. Roux FE, Reddy M: Neurosurgical work during the Napoleonic Wars: Baron Larrey's experience. Clin Neurol Neurosurg 115:2438-2444, 2013

22. Schoenfeld AJ, Mok JM, Cameron B, Jackson KL, Serrano JA, Freedman BA: Evaluation of immediate postoperative complications and outcomes among military personnel treated for spinal trauma in Afghanistan: a cohort-control study of 50 cases. J Spinal Disord Tech 27:376-381, 2014

\section{Disclosures}

The authors report no conflict of interest concerning the materials or methods used in this study or the findings specified in this paper.

\section{Author Contributions}

Conception and design: Dagain. Drafting the article: Aoun, Sellier. Critically revising the article: Aoun, Bernard, Delmas, Dulou. Reviewed submitted version of manuscript: Desse, Beucler, Fouet. Administrative/technical/material support: Dagain, Joubert. Study supervision: Dulou.

\section{Correspondence}

Arnaud Dagain: Hôpital d'instruction des Armées Sainte Anne, Toulon, France.dr.adagain@gmail.com. 